\title{
ESTUDO GEOFÍSICO DE VAZAMENTO CONTROLADO DE ÁLCOOL COMBUSTÍVEL EM ESCALA LABORATORIAL
}

\author{
Leonardo Zani Castello ${ }^{1}$, César Augusto Moreira ${ }^{2}$ e Antonio Celso de Oliveira Braga ${ }^{3}$ \\ Recebido em 19 julho, 2010 / Aceito em 27 dezembro, 2010 \\ Received on July 19, 2010 / Accepted on December 27, 2010
}

\begin{abstract}
The ethanol is used an extensive form as fuel for vehicles in Brazil, due so much to characteristics as favorable climate for sugar cane cultivation alliance with a productive chain quite developed, as the energy efficiency and almost non-existent tenor of pollutant emitted in your combustion. The wide distribution net for attendance to the final consumer represents a constant risk of leaks and contamination of rivers, soil and groundwater. This paper discusses the results of the geophysical monitoring in laboratory scale experiment, resultant of the controlled leak of ethanol in sediments partially saturated in water. The extensive application of electrical methods in environmental studies and significant alterations of electric resistivity caused in the geological environment due the presence of exogenous compositions they justify the selection of this method. There was an increase of the values in the beginning of the experiment to the maximum around $52 \mathrm{~h}$, followed for fall accentuated up to $342 \mathrm{~h}$ and happened by slow and constant growth of the values up to $2,742 \mathrm{~h}$, when compared to previous values without ethanol addition. The data suggest a temporary relationship among variations of electric resistivity to the geochemistry behavior of the ethanol in geological environment.
\end{abstract}

Keywords: electrical resistivity, logging, ethanol, monitoring.

RESUMO. 0 etanol é utilizado de forma extensiva como combustível para veículos automotores no Brasil, devido tanto a características como ao clima favorável ao cultivo de cana-de-açúcar em uma cadeia produtiva bastante desenvolvida quanto à eficiência energética e ao teor quase inexistente de poluentes emitidos em sua combustão. A ampla rede de distribuição para atendimento ao consumidor final representa um risco constante de vazamentos e contaminação de rios, solo e água subterrânea. Este trabalho discute os resultados do monitoramento geofísico num experimento em escala de laboratório, resultante do vazamento controlado de etanol em sedimentos parcialmente saturados em água. A extensa aplicação de métodos elétricos em estudos ambientais e alterações significativas em termos de resistividade elétrica, provocada no ambiente geológico pela presença de compostos exógenos, justifica a seleção do método. Houve um aumento dos valores no início do experimento até 0 máximo em torno de 52h, seguido por queda acentuada até 342h e sucedido por crescimento lento e constante dos valores até $2.742 \mathrm{~h}$, quando comparados a valores prévios sem adição de etanol. Os dados sugerem uma relação temporal entre variações de resistividade elétrica e o comportamento geoquímico do etanol no ambiente geológico.

Palavras-chave: resistividade elétrica, perfilagem, etanol, monitoramento.

\footnotetext{
${ }^{1}$ Pós-graduação em Geociências e Meio Ambiente, Instituto de Geociências e Ciências Exatas - IGCE, Universidade Estadual Paulista - UNESP, Av. 24A, 1515, Jardim Bela Vista, Caixa Postal 178, 13506-900 Rio Claro, SP, Brasil. Tel./Fax: (19) 3526-9313 - E-mail: leonardocastello@yahoo.com.br

2 Departamento de Geologia Aplicada - DGA, Universidade Estadual Paulista - UNESP, Av. 24A, 1515, Jardim Bela Vista, 13506-900 Rio Claro, SP, Brasil. Tel./Fax: (19) 3526-9313 - E-mail: moreirac@rc.unesp.br

3Universidade Estadual Paulista - UNESP, Av. 24A, 1515, Jardim Bela Vista, Caixa Postal 178, 13506-900 Rio Claro, SP, Brasil. Tel./Fax: (19) 3526-9313

-E-mail: acobraga@rc.unesp.br
} 


\section{INTRODUÇÃo}

Devido à necessidade mundial de reduzir as emissões de gases causadores do efeito estufa, como o monóxido de carbono, que é emitido pela queima de combustíveis fósseis, é pertinente 0 desenvolvimento de modelos energéticos alternativos que resultem na redução de impactos ao meio ambiente, frequentemente oriundos da emissão de gases tóxicos à atmosfera ou pela contaminação do meio geológico por vazamentos.

Frente ao grande potencial de produção do etanol como combustível para veículos movidos por motores à combustão no Brasil, sobretudo pelo clima favorável e a vasta área disponível para a plantação da cana-de-açúcar, este combustível é amplamente utilizado no transporte e utilização para esses veículos.

Os combustíveis fósseis, como a gasolina e o óleo diesel, são constituídos por hidrocarbonetos, sobretudo os compostos BTEX (benzeno, tolueno, etilbenzeno e xileno) e são classificados como LNAPL (fase líquida leve não aquosa), além de serem imiscíveis com água. 0 etanol (álcool combustível) é de origem orgânica, obtido por meio da destilação do melaço da cana-deaçúcar, e apresenta grande miscibilidade em água.

A gasolina brasileira possui uma característica peculiar, ou seja, apresenta álcool anidro (100\% etanol) em sua composição para melhorar o desempenho no motor e reduzir as emissões de poluentes. 0 álcool foi uma solução brasileira como alternativa ao petróleo e o seu teor presente na gasolina pode variar de 20\% a 24\% conforme a Lei Federal n 10.203, de 23/02/2001.

0 álcool etílico ou etanol pode ser hidratado ou anidro. 0 álcool hidratado, normalmente produzido pela destilação a partir da fermentação de biomassa, contém cerca de $95 \%$ de etanol em água, sendo utilizado nos veículos com motores a álcool após um processo posterior de destilação resulta no álcool anidro para ser adicionado à gasolina. Esta mistura torna a gasolina parcialmente miscível em água.

Devido ao uso intenso desses combustíveis, existe uma ampla rede de transporte e distribuição, sendo frequente a ocorrência de vazamentos com impacto direto nos solos e águas subterrâneas. A identificação e o diagnóstico de áreas contaminadas é um procedimento necessário a fim de que seja possível tomar medidas de contenção da fonte poluidora e posterior remediação.

Os métodos geofísicos são utilizados principalmente nas fases de prevenção, para caracterização geológica e identificação de áreas vulneráveis, como terrenos com elevada permeabilidade e nível freático raso. Nas etapas de avaliação preliminar e diagnóstica, a geofísica pode ser aplicada para delimitação 2D e 3D de plumas de contaminação, e determinação das áreas de maior concentração de contaminantes.

Aplicações recentes da geofísica envolvem o monitoramento de áreas contaminadas por compostos derivados do petróleo, por meio da avaliação temporal para controle de fluxo, redução dos teores e possíveis alterações físico-químicas resultantes da dispersão, diluição e degradação dos compostos (Moreira \& Dourado, 2007; Moreira et al., 2007; Moreira \& Braga, 2009).

Experimentos controlados, sejam em campo ou em escala de laboratório, são fundamentais para definição de comportamentos e valores esperados, principalmente para produtos passíveis de alteração ou degradação no ambiente geológico. Nesta linha de pesquisa é possível destacar diversos trabalhos.

Visando um estudo acerca do comportamento da gasolina com $20 \%$ de etanol (E-20) e da gasolina pura, Ferreira et al. (2004) simularam um vazamento em escala laboratorial por meio de colunas de sedimentos. Os resultados apontam a maior solubilidade da gasolina E-20 em relação à gasolina pura, devido a efeitos de cossolvência entre 0 etanol e a água presente no subsolo.

Estudos geofísicos em escala laboratorial foram realizados por Atekwana et al. (2000), para avaliação do comportamento geoelétrico em locais contaminados por combustíveis fósseis. Os autores apontam que em locais onde ocorram alterações químicas significativas do hidrocarboneto, devem ocorrer mudanças na assinatura geoelétrica de resistiva para condutiva. Afirmam ainda que é possível a existência dessa zona condutiva devido à biodegradação do contaminante.

Estudos geofísicos de contaminações de aquíferos por combustíveis fósseis em escala laboratorial foram realizados por Cassidy et al. (2001). Os autores sugerem que a biodegradação desses compostos sob condições aeróbicas e anaeróbicas podem ocasionar mudanças consideráveis nas condições biogeoquímicas do aquífero, com queda drástica de resistividade elétrica.

0 estudo de Braga et al. (2008) monitorou a dinâmica de evolução de uma contaminação em escala laboratorial com 0 objetivo de determinar o comportamento temporal do hidrocarboneto em relação ao parâmetro físico resistividade elétrica. Os resultados sugerem um aumento da resistividade associada aos primeiros períodos pós-contaminação, seguida de uma relativa estabilidade e posterior queda dos valores e tendência de retorno às condições naturais.

Contudo, praticamente inexistem estudos que abordem os efeitos causados pela presença de etanol no meio geológico. Diante desta deficiência de estudos, se torna relevante 0 desenvolvimento de pesquisas que abordem este tema. 


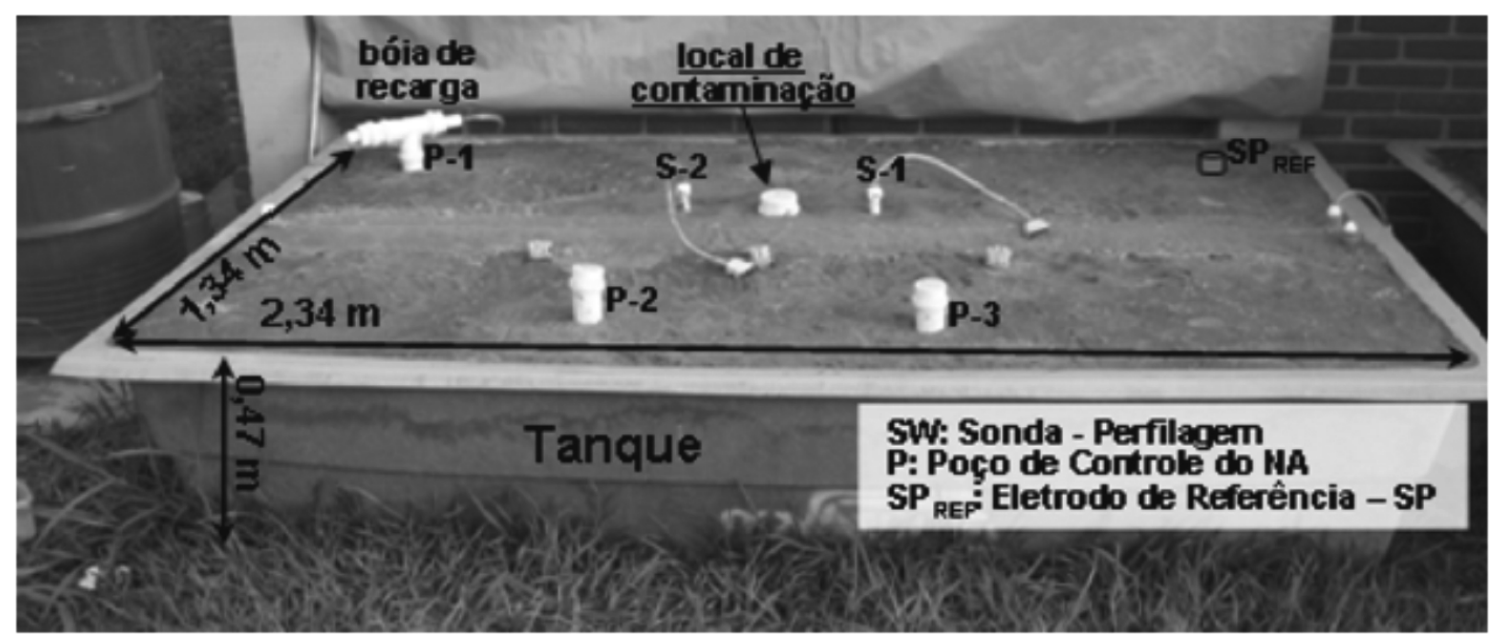

Figura 1 - Foto do local de desenvolvimento da pesquisa.

0 presente trabalho discute os resultados do uso do método geofísico da eletrorresistividade no monitoramento de um experimento em escala laboratorial, que simula o vazamento de álcool combustível em sedimentos arenosos, com objetivo de avaliar 0 comportamento do parâmetro resistividade elétrica durante 2.742 horas e determinar tendências de variação que permitam estimar 0 tempo de retorno as condições naturais anteriores a adição de álcool neste ambiente.

\section{Descrição do experimento}

Os ensaios geofísicos foram desenvolvidos em um tanque de fibra de vidro, com as seguintes dimensões na parte útil: 2,34m (comprimento) $\times 1,34 \mathrm{~m}$ (largura) $\times 0,47 \mathrm{~m}$ (altura), preenchido por areia de granulometria fina a média (Fig. 1). Nesse tanque foi simulado vazamento de álcool combustível.

Foi mantido de forma constante um horizonte insaturado $\mathrm{e}$ um horizonte saturado, por meio da permanência de um nível freático a uma profundidade média de $10,0 \mathrm{~cm}$. Para 0 controle da saturação no tanque, foram instalados três poços de controle (P), construídos com tubos de PVC, com 50,0cm de comprimento e 6,0cm de diâmetro.

Pequenos furos na parte inferior permitiram a entrada de água no sistema. Com o objetivo de estabelecer a mínima variação do nível freático, a recarga do sistema foi mantida partir de um sistema de controlado de abastecimento instalado no poço P-1.

As leituras do parâmetro resistividade elétrica foram realizadas por meio de duas sondas (S) instaladas desde a superfície até a base do tanque, na posição vertical. 0 vazamento simulado foi efetivado de forma pontual no centro do tanque, por meio da introdução de 20 litros de álcool combustível.

\section{Procedimento de aquisição de dados}

Esta é uma técnica consagrada em investigações geofísicas no interior de furos de sondagem em solo e rocha, cujo princípio foi adaptado as especificidades do presente experimento, sob a forma de duas sondas com 21 eletrodos confeccionados em anéis de chumbo (Fig. 2).

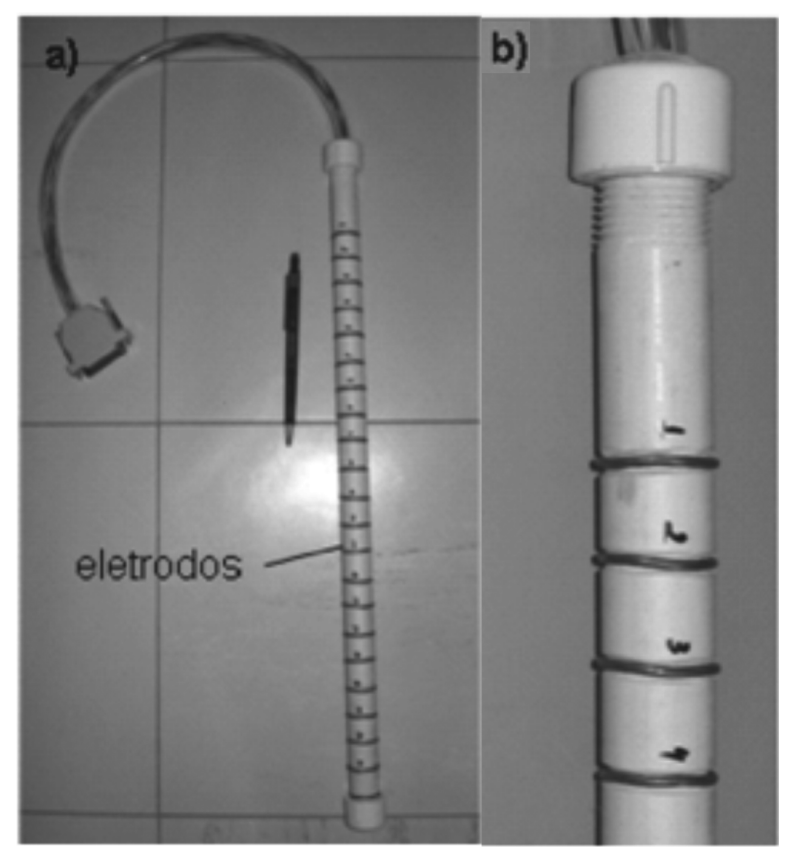

Figura 2 - Sonda utilizada na perfilagem elétrica (a); detalhe (b).

0 arranjo polo-dipolo foi utilizado nas leituras, com espaçamento $A M=M N=a=4,0 \mathrm{~cm}$, com deslocamento das leituras a cada 2,0cm, cujo ponto de atribuição da leitura é o local do eletrodo M (Fig. 3) 


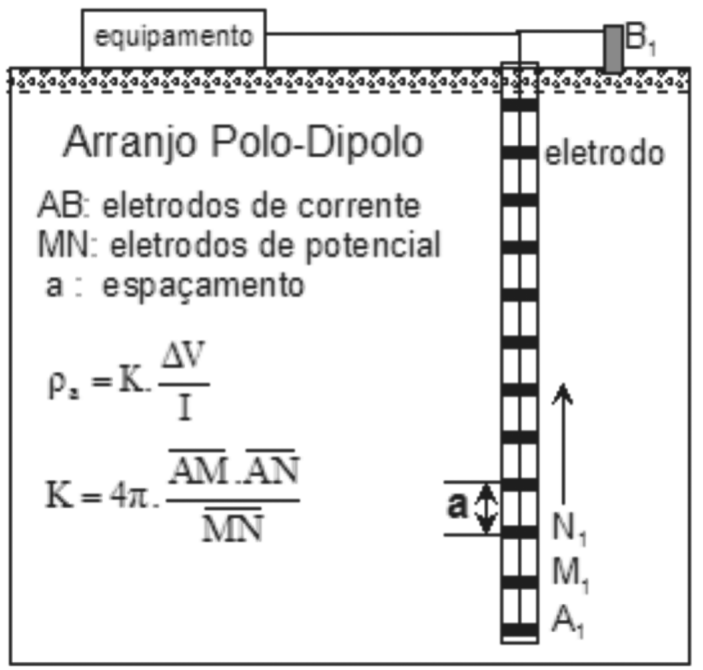

Figura 3 - Esquema do procedimento de aquisição de dados.

Foi utilizado o resistivímetro Terrameter SAS 4000, fabricado pela ABEM (Suécia), com resolução de $1 \mu \mathrm{V}$. Este equipamento é calibrado para medidas de resistividade por meio de ciclos periódicos de corrente elétrica alternada e de baixa frequência, procedimento que permite a filtragem de ruídos do sinal adquirido.

A razão $V / I$, ou seja, potencial $(V)$ pela corrente $(I)$ transmitida permite leituras diretas de resistência elétrica em ohms $(\Omega)$ (Orellana, 1976). A resistência medida é multiplicada pelo fator $K$, que representa o espaçamento dos eletrodos em superfície e resulta no parâmetro resistividade aparente (Eq. 1):

$$
\rho a=K \frac{\Delta V}{I} \Omega . m
$$

\section{Apresentação e discussão dos resultados}

Os dados são apresentados sob a forma de gráfico tempo $\times$ resistividade elétrica, para quatro profundidades fixas distintas e representam a média das leituras das duas sondas utilizadas no experimento (Fig. 4). As medidas para $6 \mathrm{~cm}$ de profundidade coincidem com a zona insaturada do experimento, enquanto que as demais foram mantidas na zona saturada.

Os dados apresentam um padrão de variação que independe do grau de saturação em água. Em termos gerais, ocorre aumento nos valores após 0 início do experimento, seguido por queda acentuada e sucedido por crescimento lento e constante dos valores.

Há um padrão semelhante de variação entre as medidas para $2,6 \mathrm{~cm}$ e $7,7 \mathrm{~cm}$, com valores máximos pouco acima de $900 \Omega$.m. 0 valor máximo das medidas para $13 \mathrm{~cm}$ está em torno

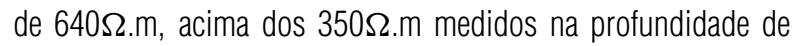

$19 \mathrm{~cm}$. Desta forma, há uma relação inversa entre os valores máximos de resistividade e a profundidade das medidas.

Após $342 \mathrm{~h}$ as medidas para os quatro níveis praticamente coincidem no extremo mais baixo dos valores, em torno de $60 \Omega$.m. A partir deste ponto, ocorre um retorno gradual aos valores de resistividade anteriores ao vazamento de álcool (Fig. 4).

A tendência de aumento gradativo e constante das medidas para as quatro profundidades, entre $342 \mathrm{~h}$ e $2.742 \mathrm{~h}$, permitiu 0 ajuste de linhas de tendência e respectivas equações de reta (Fig. 5).

Em todos os casos, houve um ajuste bastante razoável das linhas aos dados medidos. 0 valor de resistividade para as profundidades de $2,6 \mathrm{~cm}, 7,7 \mathrm{~cm}, 13 \mathrm{~cm}$ e $19 \mathrm{~cm}$ antes do vazamento de álcool no experimento, são respectivamente $200 \Omega . m, 180 \Omega . m$, $155 \Omega$.m e $100 \Omega$.m.

A partir das equações de reta é possível estimar o tempo de retorno dos valores ao padrão medido antes do vazamento de álcool no experimento. Para as profundidades de $2,6 \mathrm{~cm}, 7,7 \mathrm{~cm}$, $13 \mathrm{~cm}$ e $19 \mathrm{~cm}$ serão necessário, respectivamente $2.751 \mathrm{~h}, 2.785 \mathrm{~h}$, $2.738 \mathrm{~h}$ e $2.769 \mathrm{~h}$ para retorno aos valores de resistividade anteriores ao experimento.

É de fundamental importância conhecer 0 comportamento químico álcool no ambiente geológico para uma interpretação adequada dos resultados.

A biodegradação de etanol consiste numa reação de oxidação/redução realizada durante o processo respiratório microbiano. Durante a oxidação do composto ocorre doação de elétrons para os microorganismos, ou seja, uma reação de oxidação com o objetivo de obtenção de energia para o metabolismo microbiano, produção e manutenção celular (Grady et al., 1999).

Doadores de elétrons podem ser compostos orgânicos diversos, dentre os quais está o etanol. Este processo ocorre primordialmente durante a degradação, onde 0 oxigênio atua como receptor de elétrons e 0 composto orgânico como doador de elétrons (Grbic-Galic \& Vogel, 1987; Beller et al., 1992).

A reação de biodegradação aeróbica do etanol necessita de grandes quantidades de oxigênio, a ponto de em muitos casos transformar um ambiente inicialmente aeróbico num ambiente anaeróbico.

No caso do ambiente criado para o desenvolvimento do projeto que envolveu a contaminação por etanol e medidas geofísicas, a perda de água por evaporação foi continuamente reposta por um sistema de estabilização do nível freático. Desta forma, a recarga constante de água pressupõe uma reposição contínua do oxigênio no sistema, que colabora para a predominância de condições aeróbicas durante a aquisição de dados geofísicos. 


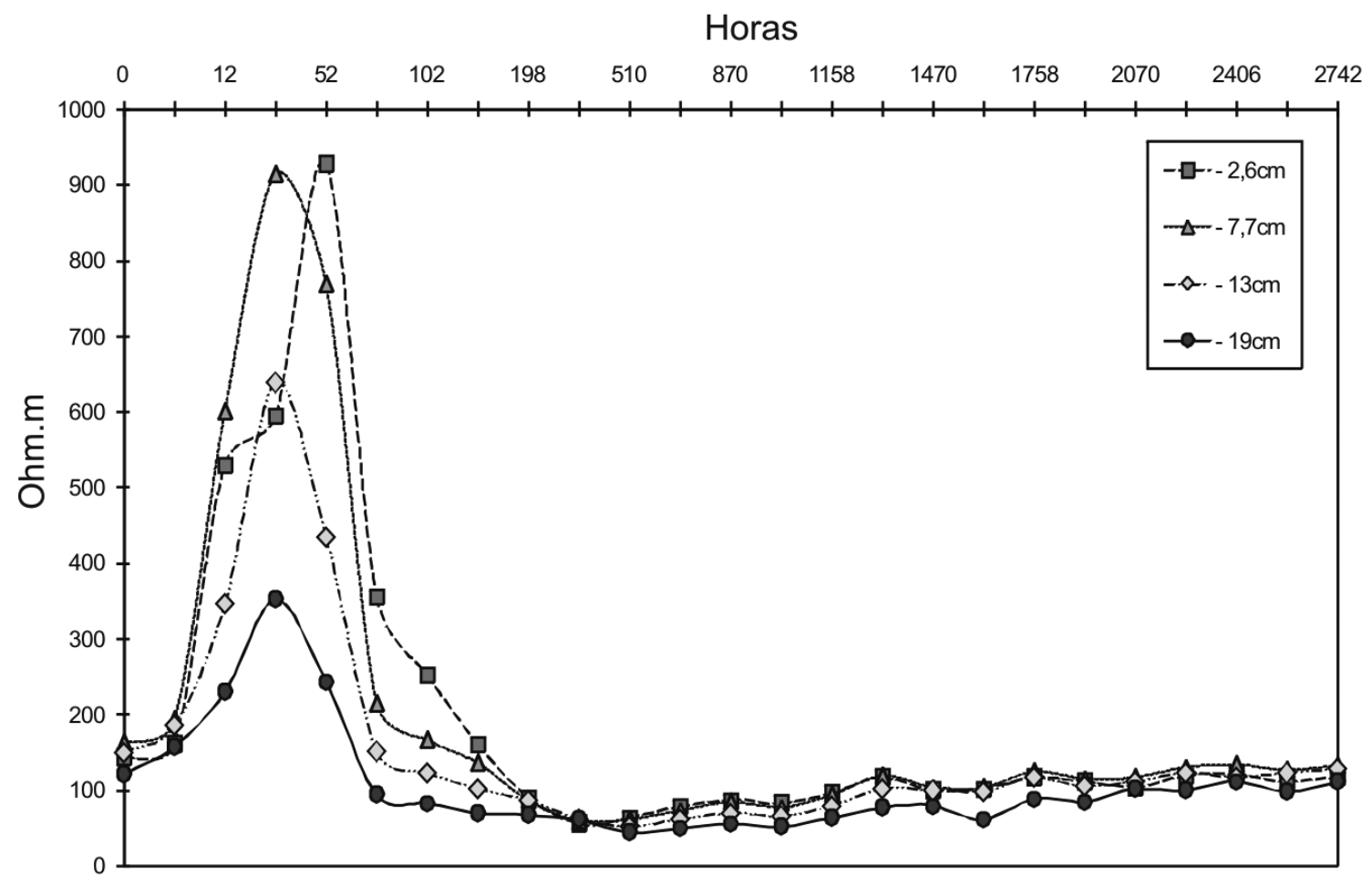

Figura 4 - Medidas de resistividade elétrica em função do tempo para quatro profundidades distintas.

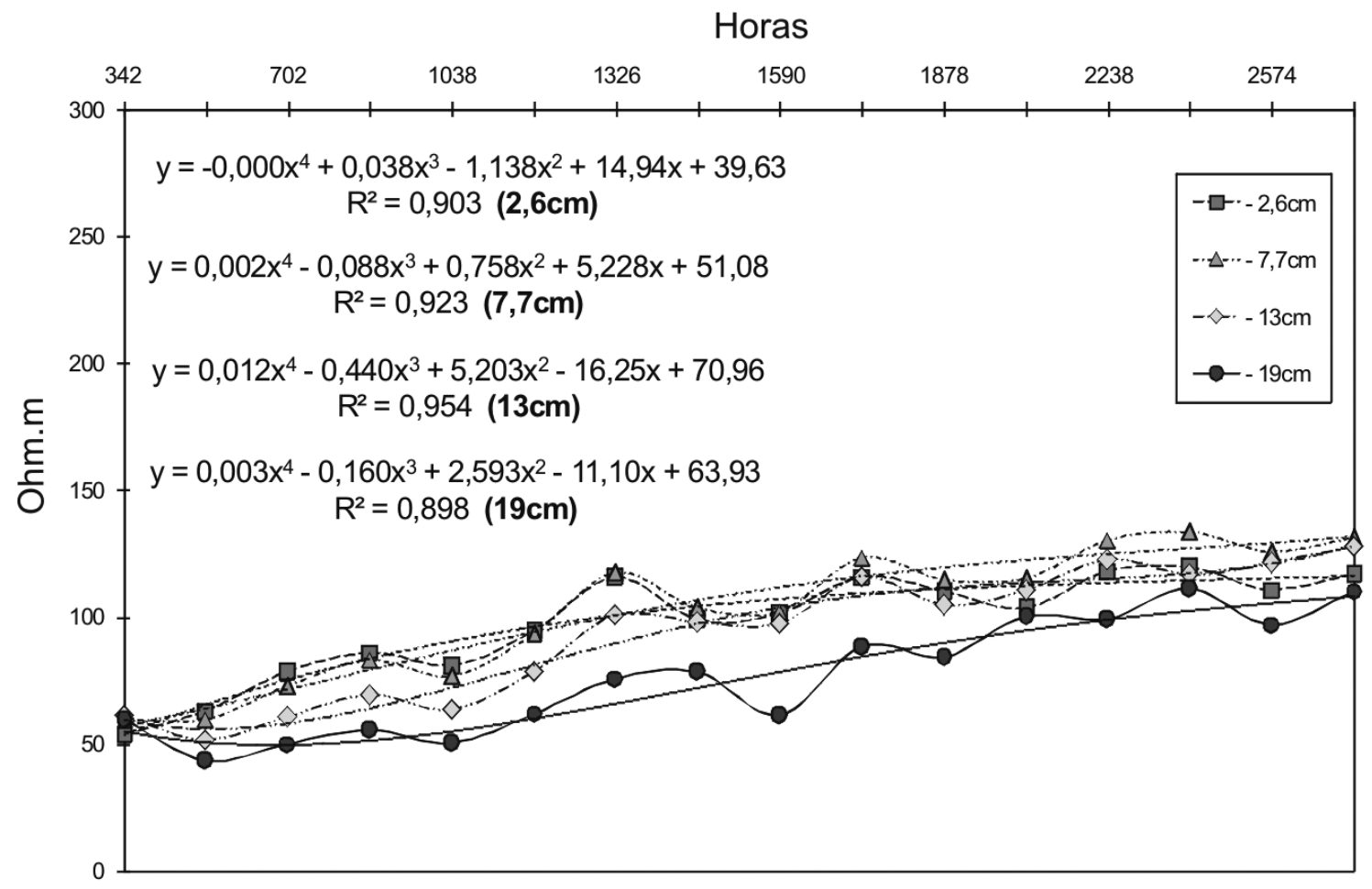

Figura 5 - Linhas de tendência e equações de reta para as quatro profundidades de leitura de resistividade, entre 342h e 2.742h. 


\section{CONCLUSÕES}

Foi possível estabelecer uma relação temporal entre variações no parâmetro físico resistividade elétrica e o comportamento geoquímico do álcool combustível no ambiente geológico, sob condições atmosféricas.

Este parâmetro físico demonstra ser altamente susceptível a alterações composicionais em fluidos de saturação no ambiente geológico, bem como eventuais modificações, como solubilização, precipitação e decomposição de compostos ou elementos em solução, conforme demonstrado neste e em diversos trabalhos de aplicação da eletrorresistividade em áreas contaminadas.

Os resultados estimados para retorno aos valores de resistividade anteriores ao vazamento de álcool devem refletir 0 tempo necessário para completa oxidação do álcool e seu total desaparecimento do experimento, sob a forma de água e gás carbônico.

Embora não tenha havido análises químicas em amostras de água após o final do experimento para comprovação da total conversão do álcool em água e gás carbônico, as alterações de resistividade monitoradas ao longo ao experimento e a tendência de retorno aos valores anteriores ao vazamento de álcool, revelam a sensibilidade dos métodos geoelétricos em estudos de monitoramento de processos de remediação de áreas contaminadas, principalmente por produtos susceptíveis a degradação e conversão total em subprodutos que não deixam resíduos no ambiente geológico.

A semelhança entre os valores previstos para total conversão do álcool na zona saturada indica a elevada miscibilidade em água e sua dissolução de forma homogênea.

A proximidade entre os valores a zona saturada e insaturada é provavelmente atribuída à eficiência no sistema de reposição de água do experimento. 0 resultado da contínua oxigenação do sistema o tornou tão eficaz quanto as condições de oxidação na zona insaturada, que disponibiliza teores de oxigênio muito superiores quando comparados à água em reações químicas que demandam este elemento.

A forma construtiva e o rigor no monitoramento e controle do experimento contribuíram para medidas precisas e estimativas temporais de alta confiabilidade, que podem ser utilizadas como parâmetros de referência em estudos geofísicos de casos reais de vazamentos e contaminações no ambiente geológico.

\section{REFERÊNCIAS}

ATEKWANA EA, SAUCK WA \& WERKEMA Jr DD. 2000. Investigations of geoelectrical signature at a hydrocarbon contaminated site. Journal of Applied Geophysics, 44: 167-180.

BELLER HR, GRBIC-GALIC D \& REINHARD M. 1992. Microbial degradation of toluene under sulfate-reducing conditions and influence of iron on the processes. Applied and Environmental Microbiology, 58(3): 786793.

BRAGA ACO, MOREIRA CA \& CARDINALLI MT. 2008. Variação temporal da resistividade elétrica em contaminação por gasolina. Geociências, 27(4): 517-525.

CASSIDY DP, WERKEMA Jr DD, SAUCK W, ATEKWANA E, ROSSBACH $S$ \& DURIS J. 2001. The Effects of LNAPL Biodegradation Products on Electrical Conductivity Measurements. Journal of Environmental \& Engineering Geophysics, 6(1): 47-52.

FERREIRA MF, OLIVEIRA E \& DUARTE U. 2004. Comportamento da gasolina com etanol (E-20) e da gasolina pura após a simulação de um vazamento em colunas de laboratório. Revista do Instituto de Geociências-USP, 4(2): 91-102.

GRADY CPL, DAIGGER GT \& LIM H. 1999. Biological wastewater treatment. Marcel Dekker, New York, 2 ed., 1096 p.

GRBIC-GALIC D \& VOGEL TM. 1987. Transformation of Toluene and Benzene by Mixed Methanogenic Cultures. Applied and Environmental Microbiology: American Society for Microbiology, 53(2): 254-260.

MOREIRA CA \& BRAGA ACO. 2009. Aplicação de métodos geofísicos no monitoramento de área contaminada sob Atenuação Natural. Revista de Engenharia Sanitária e Ambiental, 14(2): 257-264.

MOREIRA CA \& DOURADO JC. 2007. Monitoramento da Atenuação Natural de pluma de contaminação pelo método de Radar de Penetração no Solo (GPR). Revista Brasileira de Geofísica, 25(4): 389-398.

MOREIRA CA, AQUINO WF \& DOURADO JC. 2007. Aplicação do método Eletromagnético Indutivo (EM) no monitoramento de contaminantes em subsuperfície. Revista Brasileira de Geofísica, 25(4): 413-420.

ORELLANA E. 1976. Prospección Geoeléctrica en Corriente Continua. Biblioteca Técnica Philips, Madrid: Paraninfo, 523 p. 


\section{NOTAS SOBRE OS AUTORES}

Leonardo Zani Castello. Bacharel em Física pela Universidade Estadual Paulista - UNESP/Campus de Rio Claro (2008). Mestre em Geociências pela Universidade Estadual Paulista - UNESP/Campus de Rio Claro (2010).

César Augusto Moreira. Bacharel em Geologia pela Universidade Estadual Paulista - UNESP/Campus de Rio Claro (2003). Doutorado em Geociências pela Universidade Estadual Paulista, UNESP/Campus de Rio Claro-SP (2009). Trabalhou como professor Adjunto nos cursos de graduação em Geofísica e Geologia na Universidade Federal do Pampa, UNIPAMPA entre 2009 e 2011. Atualmente é Professor Assistente Doutor vinculado ao Departamento de Geologia Aplicada, IGCEUNESP/Rio Claro-SP. Áreas de interesse: Meio Ambiente, Mineração, Hidrogeologia e Geologia de Engenharia.

Antonio Celso de Oliveira Braga. Bacharel em Geologia pela Universidade Estadual Paulista - UNESP/Campus de Rio Claro (1978). Doutor em Geociências pela Universidade Estadual Paulista - UNESP/Campus de Rio Claro (1997). Trabalhou no Instituto de Pesquisas Tecnológicas do Estado de São Paulo - IPT (1978 a 1995). Desde 1998 é Professor Doutor do Departamento de Geologia Aplicada - IGCE/UNESP - Rio Claro, atuando com geofísica aplicada à hidrogeologia e estudos ambientais, envolvendo os métodos geoelétricos. 